\title{
CONTACT LENS PRACTITIONER PRACTICES IN RELATION TO PATIENT COMPLIANCE AT LIONS SIGHT FIRST EYE HOSPITAL, KENYA
}

\author{
Sheilah Nangena ${ }^{1 \mathrm{i}}$, \\ Mustafa Barasa $^{2}$ \\ ${ }^{1}$ BSc. optom, Optometry and Vision Sciences, \\ Masinde Muliro University of Science and Technology, \\ Kenya \\ ${ }_{2}^{2} \mathrm{PhD}$, Medical Laboratory Sciences, \\ Masinde Muliro University of Science and Technology, \\ Kenya
}

\begin{abstract}
:
Background: Contact lens practitioners (CLPs) play a vital role in the fitting of contact lenses (CL) and thus have a great influence on patient compliance. Studies have often focused on investigating levels of compliance and thus limited knowledge of CLP practices. Thus, this study aimed to investigate CLP practices on CL wear and care. Methods: The study employed a cross-sectional research design. Purposive sampling technique was used to select consenting CLP's working Lions Sight First Eye Hospital (LSFEH). A self-administered questionnaire, containing questions on current Practices, was used to collect information. Once ethical clearance from MMUST IERC, NACOSTI and permission LSFEH were obtained data collection process began. A total of fifteen (15) CLP participated in the study. Results: The mean age of the practitioners was $31 \pm 3.87$. Most (67\%) of the CLPs had worked for between 5 to 10 years. A majority (73\%) of the practitioners had bachelor's degree. Most (87\%) of them specialized in soft lenses. Majority of the CLP use of written appointment card, 53\% of the CLP use of manufacturer guidelines and oral communication is the most used form of training patients as said by $60 \%$ of the CLP. Conclusion: CLPs at LSFEH had good wear and care practices on patient instruction. For successful CL wear, patients need to follow instructions given by CLPs on CL wear and care. It is, therefore, necessary for CLPs to practice according to the recommended guidelines to avoid patient non-compliance.
\end{abstract}

Keywords: contact lens, contact lens wear and care, practitioners, Kenya, practices

i Correspondence: email snangena@mmust.ac.ke 


\section{Introduction}

Practitioners play a major role in the prescribing and fitting of CLs and CL care solutions. Anecdotal reports suggest that patients usually receive the care and maintenance guidelines from the practitioners and not surprising, therefore, as studies have shown that practitioners have a great influence on patient compliance $(1,2)$. Failing to explain the benefit and effects of not following the guidelines adequately, not taking into consideration the patient's lifestyle or the cost of the lenses and care solutions, and having a poor patient-practitioner relationship, can be associated with poor patient compliance (3).

Moreover, studies have shown that wearers who purchase their contact lenses from qualified contact lens practitioners are likely to be more compliant than wearers who purchase their lenses and care products over the internet (4-6). This shows the significant role played by CLP's. It is therefore important to understand practices of contact lens practitioners which may be key to further understanding compliance. In Kenya, contact lenses are prescribed by qualified optometrists or ophthalmologist. However, there is no published data on the influence of practitioners on patient compliance on the Kenyan setting. It was, therefore, necessary to investigate the Contact Lens Practitioner Practices at LSFEH in Kenya in relation to patient compliance.

Noncompliance with lens care regime is associated with contact lens-related complications (7). The risk of developing corneal infections is sixty times more among contact lens wearers compared to non-wearers (6). This is due to the increased bacterial bioburden at the ocular surface which alters ocular surface defence (8). The occurrence of these complications and symptoms of lens discomfort lead to reduced CL performance, inability to adapt to CL and eventually contact lens dropout.

Studies have had a focus on only establishing the levels of CL compliance and its determinants other than the possible role of CLPs on CL compliance by wearers. It was, therefore, important to carry out this study to better understand CLP influence on CL compliance in Kenya.

\section{Materials and Methods}

This study was conducted at Lions Sight First Eye Hospital (LSFEH). This hospital was chosen because of its large CL patient database considering that CL is not widely practised in Kenya and due to its central location in Nairobi and presence of cornea and anterior eyes specialists, making it a suitable study area. The study employed an analytic cross-sectional research design using. Optometrists practising at the LSFEH who attend to CL clients. CL practitioners who attend to least five CL patients in a week. Those who were excluded from the study was based on them being a newly graduated optometrist who has been practising CL fitting for less than six months. Those unwilling to sign the consent forms. 
Data were collected using a structured questionnaire developed using Asia Pacific guidelines on CL practices (9). The questionnaire comprised of semi-structured questions, which allowed for clarification by the study participants to the questions posed, as well as closed-ended questions. Ethical approval to conduct this study was received from the Institutional Ethics Review Committee of Masinde Muliro University of Science and Technology (MMUST IREC), while permission to conduct this study was granted by the management of LSFEH following due clarification on the purpose and benefits of the research. The study adhered to tenets of Helsinki Declaration.

Contact lens practitioners at LSFEH were invited to participate in the study using the information document. Those willing to participate provided signed consent and thereafter the questionnaire was handed to them. After which the responses were collected and kept in a secure place.

Data was entered into an MS-Excel 2016 spreadsheet and checked by the principal researcher to ensure there was no missing or wrongly entered data. The data was then exported to SPSS (version 25) for analysis.

\section{Results}

The mean age of the practitioners was 36 with a standard deviation of 3.87. Most (67\%) of the practitioners had worked for between 5 to 10 years. A majority (73\%) of the practitioners had bachelors as the highest level of education. Most (87\%) of the practitioners had specialized in soft lenses, $40 \%$ in hard lenses while only $13 \%$ said they had specialised in scleral.

\subsection{Practitioner Practices and Their Influences on Compliance}

As evident from table 1,100\% of the CLP agreed that instructions on the insertion and removal of CL are issued by optometrist while only $27 \%$ said they are issued by optical assistants. The use of written appointment card is the most common way of ensuring there is aftercare compliance as posited by 53\% of the CLP followed by leaving it to the patient to decide and use of telephonic reminders as indicated by $33 \%$. As evident from $47 \%$, the use of manufacturer guidelines is the most common source of guidelines followed by journals and textbook and the American optometric association with 33\% each. Oral communication is the most used form of training patients as said by $60 \%$ of the CLP followed by demonstrations and written communication which is being used by $47 \%$ and $40 \%$ respondents respectively. Before fitting a new CL, 67\% of the CLP said they consider motivation and interest of the patient while $47 \%$ said they consider hygiene and financial position.

The findings showed that in most cases training is personalized as said by $47 \%$ of the 15 CLP while 27\% said they normally conduct training in groups. Once a patient has been as noncompliance, $47 \%$ of the CLP said they educate and train them while $33 \%$ said they ask optical assistants to re-train the patients. A majority $(40 \%)$ of the CLPs said that manufacturer guidelines should be used to determine after how long one can change CL 
followed by those who said that they should be changed when they become foggy and unclear as evident from $27 \%$. To identify compliance, $40 \%$ of the CLP said they examine the eye and ask the patient to demonstrate. Only $20 \%$ said they never follow up on compliance. Alcohol disinfectants were the most recommended for hand washing as posited by $40 \%$ of the CLP followed by soap and water as said by $33 \%$.

Table 1: Summary of compliance responses by practitioners

\begin{tabular}{|c|c|}
\hline Question & Percentage \\
\hline \multicolumn{2}{|l|}{$\begin{array}{l}\text { Who instructs patients on the insertion and removal of their contact lenses at your } \\
\text { practice? }\end{array}$} \\
\hline Optometrist & $100 \%$ \\
\hline Optical assistant & $27 \%$ \\
\hline Receptionist & $0 \%$ \\
\hline Only written instructions provided - no actual demonstration & $0 \%$ \\
\hline Other (specify) & $0 \%$ \\
\hline \multicolumn{2}{|l|}{ How is compliance with aftercare appointments ensured? } \\
\hline Written appointment card is given & $53 \%$ \\
\hline Telephonic reminder & $27 \%$ \\
\hline It is left to the patient to decide if they will come or not & $33 \%$ \\
\hline No, follow up is usually done regarding compliance & $0 \%$ \\
\hline Other (specify) & $0 \%$ \\
\hline \multicolumn{2}{|l|}{$\begin{array}{l}\text { What are the sources of information that you base your recommended guidelines on } \\
\text { for wear and care that you give your patients? }\end{array}$} \\
\hline American optometric association & $33 \%$ \\
\hline Food and drug administration & $0 \%$ \\
\hline Journals/textbooks & $33 \%$ \\
\hline Manufacturers guidelines & $47 \%$ \\
\hline Other (specify) & $0 \%$ \\
\hline \multicolumn{2}{|l|}{ How do you get emerging information on contact lens wear and care? } \\
\hline Only when there is a problem e.g. eye pain & $47 \%$ \\
\hline After every 6 months & $27 \%$ \\
\hline When vision starts to reduce & $27 \%$ \\
\hline It's up to the patient & $7 \%$ \\
\hline Other (specify) & $0 \%$ \\
\hline \multicolumn{2}{|l|}{ What factors do you consider before fitting a new contact lens patient? } \\
\hline Journals/textbooks & $47 \%$ \\
\hline Attend training and continuing education programs on the same & $53 \%$ \\
\hline Guidelines never change & $0 \%$ \\
\hline Only written instructions provided - no actual demonstration & $0 \%$ \\
\hline Other (specify) & $0 \%$ \\
\hline \multicolumn{2}{|l|}{$\begin{array}{l}\text { In what form of communication do patients get the training information on wear and } \\
\text { care? }\end{array}$} \\
\hline Oral communication & $60 \%$ \\
\hline Written communication & $47 \%$ \\
\hline Demonstrations & $53 \%$ \\
\hline Video & $0 \%$ \\
\hline Other (specify) & $0 \%$ \\
\hline What factors do you consider before fitting a new contact lens patient? & \\
\hline
\end{tabular}




\begin{tabular}{|c|c|}
\hline Motivation and interest of the patient to wear lenses & $67 \%$ \\
\hline The financial position of the patient & $47 \%$ \\
\hline Age & $40 \%$ \\
\hline Refractive error alone & $27 \%$ \\
\hline Hygiene & $47 \%$ \\
\hline Other (Specify) & $0 \%$ \\
\hline \multicolumn{2}{|l|}{ How would you describe your contact lens wear and care training? } \\
\hline Training is personalized to fit each individual & $47 \%$ \\
\hline Training is usually done in groups because they are time-consuming & $27 \%$ \\
\hline $\begin{array}{l}\text { Training is given through videos and other instructional materials for patients to learn } \\
\text { for themselves. }\end{array}$ & $0 \%$ \\
\hline No training is given & $0 \%$ \\
\hline Other (specify) & $0 \%$ \\
\hline \multicolumn{2}{|l|}{ What action do you take when you identify a non-compliant patient? } \\
\hline Ignore & $0 \%$ \\
\hline Optical assistant re-train patient & $33 \%$ \\
\hline Educate the patient on the importance of compliance & $47 \%$ \\
\hline Stop the patient from wearing contact lenses & $40 \%$ \\
\hline Other (specify) & $0 \%$ \\
\hline After how long are patients advised to change lenses and contact lens cases? & $0 \%$ \\
\hline When lenses become foggy and unclear & $27 \%$ \\
\hline According to manufacturer-recommended guidelines & $40 \%$ \\
\hline When patients can afford to so it is up to the patient to decide & $20 \%$ \\
\hline Only in case of loss of contact lens. & $7 \%$ \\
\hline Other (specify) & $0 \%$ \\
\hline What are some of the methods of identifying patient compliance? & $0 \%$ \\
\hline Eye examination. & $40 \%$ \\
\hline Asking the patient to tell me some of the rules regarding contact lens wear and care. & $33 \%$ \\
\hline I never follow up on compliance & $20 \%$ \\
\hline Demonstration from patients on how they do it & $40 \%$ \\
\hline Other (specify) & $0 \%$ \\
\hline \multicolumn{2}{|l|}{ For hand washing what do you recommend for patients to use? } \\
\hline Soap and water & $33 \%$ \\
\hline Warm water & $0 \%$ \\
\hline Alcohol disinfectants & $40 \%$ \\
\hline Wet wipes & $0 \%$ \\
\hline Other (specify) & $0 \%$ \\
\hline
\end{tabular}

\subsection{Thematic Analysis}

Using an open-ended section on the questionnaire for Part B, practitioners were asked to give their opinions on several aspects reigning compliance and best practices of CL wearers. A summary of the responses, and the emerging theme, for each question posed, is provided below:

a. Difficulty with cleaning contact lens cases are sources of microbial infection for patients. What do you think can be done to improve or correct the problem? I In your opinion how can this be improved? 
When asked how patients can manage the challenge in cleaning CLs which leads to microbial infection for patients the respondents said that educating the wearers on how to best clean their lenses and the importance of replacing them timeously are the solutions. For instance, one practitioner said "Educate patient in contact lens handling and replace the lens regularly" while another believed "Advise the patient to throw away the old case and start using a new one; every time they buy a new bottle of solution it should come with a new case or, provide the patient with several cases and give them correct information on how often to change the case."

b. Practitioners are not spending enough time to properly educate patients on step-wise procedures involved in contact lens care and maintenance. How do you think the patient's education on contact lens care and maintenance can be improved?

The participants were asked how patient education can be improved. The responses showed that an increase in the frequency of educating patients and delegation of the responsibility are the two main solutions. One of the practitioners said "Provide proper demonstrations but also written information. Be sure to advise the patient on a regular follow-up every six months, or at least once a year. Always remind the patient of proper use and care." Concerning delegation, the respondent said "This can be achieved by empowering clinical assistants to educate patients more because they spend most of the time with the patients. This can be done by regular education."

c. There's a need for extralfree lens cases issued to patients to reduce contamination or risk of infection when misplaced. What do you think can be done to address this concern?

One solution to solve the limitations of CLs is the use of extra or free lens cases to reduce contamination. When asked what can be done to address this concern, the practitioners agreed that the provision of extra cases should be a practice. One of the respondents said, "By providing patient extra cases every time upon visiting and change of new lenses or when there are complications related to wearing".

e. Oral instructions given to patients are complex and can be easily forgotten. What do you think can be done to simplify patients' instructions?

Given the importance of information given to patients, the practitioners were asked what can be done to solve the challenge of oral instructions. The use of written and video instructions was cited by all those who took part. One of the respondents said "Also provide written information for the patient to take home. Should include pictures and not just text, also written simply and understandably." Another similar opinion was "By sending the regular educational videos, asking them to subscribe to monthly patient education from Alcon and Cooper to keep them updated." To reduce patients forgetting instructions given one practitioner said "Give them written information for them to bring and repeat the most important bullet points on each follow-up. When fitting contact lenses for the first time, I usually quiz them at the end just to make sure they've gotten the most important information." 
f. Patients hardly follow instructions and practitioners have no effective support system to ensure they adhere to given instructions. What innovative strategies can be employed to ensure practitioners better follow-up and ensure compliance with given instructions?

The practitioners were further asked what innovative strategies can be employed to ensure they better follow-up and ensure compliance with given instructions. It was clear that the use of effective reminders which are technologically driven is an innovative solution. One of the respondents said "Automatic reminders sent out to patients every 6 months. If the patient never answers, there should be a system in place to call these patients, make sure they don't fall out of the system." Another similar opinion was "By frequent reminders through their phones and explaining the importance of following the said instructions. This can further be managed by confiscating lenses that cause complications to the patient."

g. Patients often forget their aftercare visits appointments hence putting them at risk of CL complications. How can CLP help enhance patient's reminders on their aftercare visits' appointment?

Patients often forget their aftercare visits appointments hence putting them at risk of CL complications. In this regard, the respondents were asked how CLPs can help enhance patient's reminders on their aftercare visits' appointment. The use of technologically driven reminders was the solution. One the practitioner said, "Usually in the practice, I work in, we send out reminders on their phone."

h. CLPS are not updated nor trained on new technologies and advances in contact lens wear and care. How can CLPs be supported in up taking new technologies and advances in contact lens wear and care?

The study also sought to capture how CLPs can be supported to ensure that they are technologically knowledgeable to keep up with the current trends. The use of training offered by manufacturers and providers was cited by five practitioners. For instance, one said, "I think it is by contacting webinars that are geared toward effective utilization of contact lenses and ensuring a high level of training in refresher courses." Similarly, another respondent added "Manufacturers and/or the workplace should provide frequent seminars where CLP's can be updated on new technologies. In the practice where I work there are seminars throughout the year where we get new information, so we are always up to speed."

i. Best way to know if a patient is compliant is to follow them up and find out about their contact lens wear and care behaviour. What ways can CLP get information from patients on their understanding and practice of CL related hygiene regime so that the CLP could identify and correct areas of improvement?

The study sought to explore ways by which the CLP can get information from patients on their understanding and practice of CL related hygiene regime so that the CLP could identify problematic areas and suggest areas of improvement. The use of regular communication with the patient was one of the approaches. One CLP said, "By periodic 
communication through the mobile phones and giving patient charts to monitor the contact lens finding if they deviate from the normallexpected findings."

j. Further suggestions on how contact lens compliance, particularly with wear and care, can be improved.

The respondents were asked to give further suggestions on how contact lens compliance, particularly with wear and care, can be improved. Regular follow-ups of patients and the sharing of information were the two recommendations. One of the CLPs suggested, "CLP's should just continue to give out information and remind their patients to be compliant with follow-ups." Another CLP suggested that "Make sure to have in place a system where you can follow your patients properly and regularly."

\section{Discussion}

\subsection{Practitioner Practices and their Influences on Compliance}

The third objective was to study compliance from the perspective of the CL practitioner, in light of best practice. Most of the practitioners had worked for between 5 to 10 years. This can be explained by the fact that the average age was 36. A majority of the practitioners had specialised in hard contact lenses followed by those who had chosen soft lenses with very few in specialising in scleral. This can be explained by market demand where $90 \%$ of the lenses are soft and RGPs.

The findings showed that it is an optometrist who instructs patients on the insertion and removal of their contact lenses. This is in line with the recommendations of the FDA) guidelines where only qualified and licenced practitioners should attend to patients seeking eye care services (Commissioner FDA, 2019). Further is more use of written cards appointment and technology reminders to ensure compliance with aftercare appointments. The practitioners also use oral and written communication when training patients on wear and care. The use of cards expressly conveys the information on aftercare. This is in line with the recommendations of Claydon et al., 1997; Walsh and Veys, 2003 who noted that medical practitioners should develop an effective way of communicating with patients to ensure that comprehend and adhere to all the information. Similarly, (13) noted that patient appointments have effectively been scheduled using mobile technology given the advent of technology through internet and smartphone. Further recommended that patient-doctor communication should be customized to meet individual needs. This explains why practitioners had personalised contact lens wear and care training to fit each individual. However, in some cases, the training is usually done in groups because they are time-consuming.

The use of manufacturers' guidelines and the American optometric association were the common sources of information used by the CLPs. The use of manufacturer guidelines in the best way to understand how contact lenses and related products should use. For instance, according to compliance in CL wear may be defined as the adhering to prescribed lens wear and care regimes according to manufacturer guidelines (7). Further, 
the practitioners used information from journals and textbooks and also attended training and continuous educational programs on the same. The journals and textbooks, and content for training are mostly based on recommended practices some of which are from the manufacturer as well as the American optometric association among other associations.

Motivation and interest of the patient to wear lenses as well as their financial position are the factors considered by practitioners before fitting a new contact lens Motivation is important given that some patients merely desire to wear contact lenses for therapeutic purposes but do not medially need those (14). For instance, children and adolescents may desire contact lenses just to be like their peers. The study noted that financial constraint is one of the barriers to contact lens compliance. As such some practitioners are persuaded to consider if one can afford contact lenses and necessary care as well as replacement schedules before offering recommendations.

From the findings, it is evident that practitioners educate and retain patients when they identify non-compliance. Notably, no practitioner said that they ignore noncompliance. It is important to re-train patients on the importance of following contact lens use recommended practices. One of the main information passed across in reduction of infections and increasing durability of the lenses (15). This is in line with the findings of Mohd-Ali and Tan (2019) who noted that retraining is one of the methods of improving patient education and attitudes toward compliance with instructions for contact lens use. Noncompliance is detected through an eye examination and asking the patient to explain their contact lens wear and care. The eye examination can show the effects of noncompliance such as infection (15).

\section{Conclusion}

Contact lenses are medical devices as approved by the FDA and as such they should be used according to the recommenced guidelines. Practitioners play an important role in educating and training CL wearers on the effective use of these devices. For successful CL wear, patients need to follow instructions given by CLPs on CL wear and care. It is, therefore, necessary for CLPs to practice according to the recommended guidelines to avoid patient non-compliance.

\section{Conflict of Interest}

No conflict of interest.

\section{Funding}

None. 


\section{References}

1. Bui TH, Cavanagh HD, Robertson DM. Patient compliance during contact lens wear: Perceptions, awareness, and behavior. Eye Contact Lens. 2010;36(6):334-339.

2. Livi S, Psych D, Zeri F, Optom D, Psych ID, Fbcla F, et al. Contact Lens and Anterior Eye Health beliefs affect the correct replacement of daily disposable contact lenses : Predicting compliance with the Health Belief Model and the Theory of Planned Behaviour. Contact Lens Anterior Eye. 2016;40(1):25-32.

3. Donshik PC, Ehlers WH, Suchecki JK, Anderson LD. Strategies to Better Engage, Educate, and Empower Patient Compliance and Safe Lens Wear: Compliance : What We Know, What We Do Not Know, and What We Need to Know. 2007;33(6):430-433.

4. Claydon BE, Efron N. Non-compliance in contact lens wear. Ophthalmic Physiol Opt J Br Coll Ophthalmic Opt Optom. 1994 Oct;14(4):356-64.

5. Dumbleton KA, Richter D, Woods CA, Aakre BM, Plowright A, Morgan PB, et al. Contact Lens \& Anterior Eye A multi-country assessment of compliance with daily disposable contact lens wear. Contact Lens Anterior Eye. 2013;36(6):304-312.

6. Morgan PB, Efron N, Toshida H, Nichols JJ. An international analysis of contact lens compliance. Vol. 34, Contact lens \& anterior eye : the journal of the British Contact Lens Association. 2011. p. 223-8.

7. Jinabhai AN. Contact Lens Compliance. In Bosh and Lomb Academy of Vision; 2013.

8. Wu YT, Zhu H, Harmis NY, Iskandar SY, Willcox M, Stapleton F. Profile and Frequency of Microbial. 2010;87(3):152-8.

9. Sweeney, Brien Holden, Kylie Evans, Venice Ng, Pauline Cho. OPTOMETRY Best practice contact lens care: A review of the Asia Pacific Contact Lens Care Summit. 2009;78-89.

10. Commissioner O of the. Focusing on Contact Lens Safety. FDA [Internet]. 2019 Mar 22 [cited 2019 Jun 1]; Available from: http://www.fda.gov/consumers/consumerupdates/focusing-contact-lens-safety

11. Claydon BE, Efron N, Woods C. A prospective study of the effect of education on non-compliant behaviour in contact lens wear. Ophthalmic Physiol Opt J Br Coll Ophthalmic Opt Optom. 1997 Mar;17(2):137-46.

12. Walsh K, Veys J. Encourage compliance not complacency. 2003;

13. Kayambile G, Kalegele Khamisi. (PDF) Enhancing Patient Appointments Scheduling that Uses Mobile Technology [Internet]. 2015 [cited 2020 Jun 2]. Available from:

https://www.researchgate.net/publication/293793908_Enhancing_Patient_Appointment s_Scheduling_that_Uses_Mobile_Technology

14. Abokyi S, Manuh G, Otchere H, Ilechie A. Knowledge, usage and barriers associated with contact lens wear in Ghana. Contact Lens Anterior Eye J Br Contact Lens Assoc. 2017 May 19;40. 
15. Lievens CW, Cilimberg KC, Moore A. Contact lens care tips for patients: an optometrist's perspective. Clin Optom. 2017 Aug 11;9:113-21. makes clear that the materials are being reused under permission of a Creative Commons License. Views, opinions and conclusions expressed in this research article are views, opinions and conclusions of the author(s). Open Access Publishing Group and European Journal of Public Health Studies shall not be responsible or answerable for any loss, damage or liability caused in relation to/arising out of conflicts of interest, copyright violations and inappropriate or inaccurate use of any kind content related or integrated into the research work. All the published works are meeting the Open Access Publishing requirements and can be freely accessed, shared, modified, distributed and used in educational, commercial and non-commercial purposes under a Creative Commons Attribution 4.0 International License (CC BY 4.0). 